\title{
Influencia cultural de la religión católica en Filipinas
}

$\mathrm{E}$ 1 término cultura ha sido discutido ampliamente; de hecho, comúnmente se le identifica como el conjunto de conocimientos adquiridos; sin embargo, desde un punto de vista antropológico, el término tiene otro significado. Por ejemplo, para Alfonso Caso, que tiene esa visión, no puede haber hombre sin cultura, ya que su significado es el conjunto de ideas, métodos, prácticas, instrumentos, y objetos que esa sociedad elabora para satisfacer sus necesidades. ${ }^{1}$

Por otro lado, el concepto de aculturación, se entiende como la adaptación de un pueblo menos desarrollado a la cultura de otro más desarrollado por su contacto con este último. Por ejemplo, la influencia de la cultura de España en el pueblo filipino se identifica con el término de aculturación. La forma en que se define ha desatado muchas polémicas en el sentido de que refleja el predominio de la influencia cultural que tiene un país desarrollado en otro. Una definición quizá más conservadora es la siguiente:

“...aculturación es el conjunto de fenómenos que resultan porque unos grupos de individuos de culturas diferentes entran en contacto continuo y directo con los consiguientes cambios que surgen en los modelos culturales originales de uno de los otros grupos". ${ }^{2}$

En este sentido, la aculturación puede darse en cualquiera de los grupos, independientemente de cuál sea el desarrollado; de hecho, es posible que podamos encontrar influencias en forma recíproca; sin embargo, es más frecuente distinguir la influencia de la cultura dominante sobre la subdesarrollada.

En 1940, el cubano Fernando Ortiz propuso cambiar el concepto de aculturación por

* Investigador del Departamento de Estudios del Pacífico de la Universidad de Guadalajara. el de transculturación, ya que según este último el concepto de transculturación expresa de una mejor manera el proceso de transición de una cultura a otra, con lo cual nos llevaría a una asimilación de la cultura extraña, y también al mismo tiempo a una deculturación de la propia cultura. ${ }^{3}$

Existen así una diversidad de conceptos y de propuestas nuevas sobre la denominación de aculturación, así como de las formas en que el proceso se puede dar, ya sea con dinámicas de resistencia, de sincretismos y de conveniencias de asimilación de la cultura.

\section{La religión católica y el desarrollo científico en Filipinas}

En el caso de Filipinas, seguramente podemos encontrar muchos rasgos de la cultura española en el pueblo filipino; no obstante, este artículo sólo se refiere a la influencia que podría tener la religión católica en el desarrollo de la ciencia en Filipinas. La idea y la forma de estudiar el problema, igualmente incluye a muchos otros países, sobre todo los de América Latina, que en su mayoría manifiestan este tipo de influencia cultural.

El archipiélago de Filipinas fue descubierto por Hernando de Magallanes en 1531; posteriormente, el navegante fue muerto en sus playas y la posesión española de las islas -que al mismo tiempo eran codiciadas por otras potencias- se aseguró hasta 1564.

La historia de la colonización española en Filipinas es similar a la de los países latinoamericanos, aunque destacan dos características distintivas: la ubicación en las rutas oceánicas mercantiles, lo cual permitió que el país se convirtiera en un lugar de recepción del comercio proveniente del conjunto del sudeste asiático destinado a la metrópoli, y su dependencia directa del virreinato de México. 
¿Cómo es que se da la influencia de la religión católica en el desarrollo científico? la ciencia es un producto cultural que surgió en Europa occidental como resultado de una compleja evolución histórica. Se originó debido a una serie de desarrollos sociales, como el crecimiento de las ciudades, la declinación del feudalismo, el aumento del comercio, el auge de la burguesía y el surgimiento de la sociedad capitalista. $^{4}$

La aportación de Weber de que a partir del desencantamiento de todas las imágenes religiosas y metafísica surgen estructuras de conciencia modernas, ${ }^{5}$ la considero de gran importancia, ya que nos permite explicar en parte la influencia de la religión católica en el desarrollo de la ciencia en Filipinas.

Con el renacimiento, el espíritu de éste comienza a desplazar la modalidad medieval del pensamiento europeo: la filosofía especulativa y el escolasticismo. ${ }^{6}$ La escolástica es el ejercicio de la actividad racional con la finalidad de llegar a la verdad religiosa, demostrarla o aclararla en los límites de lo posible y dotarla de un arsenal defensivo contra la incredulidad y la herejía. En este sentido, la disolución de la escolástica, que abarca desde los primeros decenios del siglo XIV hasta el renacimiento, consiste precisamente en la oposición entre la fe y la razón. ${ }^{7}$

No en todas las sociedades hubo las condiciones para la consolidación de la ciencia moderna. Es particularmente en el norte de Europa, después de la reforma, donde se dieron las condiciones materiales, sociales e ideológicas para su desarrollo. Contrariamente, en España triunfaba la contrarreforma durante la misma época en la que se difundía en Francia e Italia el espíritu del renacimiento. Asimismo, la colonización de América permitió a España atrincherarse contra el resto de Europa y convertirse en bastión del espíritu escolástico y del discurso autoritario y teocrático, que en el resto de Europa ya iba de salida. ${ }^{8}$

Debido a la grave crisis que vivió España a finales del siglo XIX, donde el sistema político no funcionaba, se acrecentaron los desfases sociales y comenzaron a surgir los primeros conflictos de violencia social, situación que se agudizó con la independencia de sus últimas colonias: Cuba y Filipinas en 1898. Tras varios años de guerra, en la literatura española de 1885 a 1914 se puede observar el reclamo de muchos escritores hacia España. Éstos se agrupan en lo que se conoce como modernismo y Generación del 98. Pedro Salinas distinguió claramente que el modernismo es un movimiento de poetas y el del 98, lo es de ideólogos. El modernismo buscaba la belleza y el del 98 la verdad. El modernismo es sintético (síntesis de diversos movimientos estéticos), frente al del de 98, que es analítico (de los problemas de España). ${ }^{9}$ Antonio Machado lo decía, en un reclamo de dos palabras, "España miserable". "La voz de Machado fue una en el coro de la generación de 1898, el año de la pérdida del imperio, que le gritaba a España: refórmate, conócete, modernízate [...] Pero primero mírate, dijo el dramaturgo Ramón del Valle Inclán."10

Así, la contrarreforma impedía a España avanzar en el desarrollo de la ciencia y su influencia sobre Filipinas tendría iguales resultados. Durante 333 años de presencia española en Filipinas, la falta de efectivos militares y la lejanía de la metrópoli propiciaron que la tutela colonial fuese virtualmente confiada a las órdenes religiosas del archipiélago.

En lo que corresponde a la influencia de la religión católica sobre la educación que se impartía en las colonias, incluyendo a Filipinas, cito algunas de las leyes de los reinos de las Indias que fueron mandadas imprimir y publicar por Carlos II:

“Ley xv.

Que el que se hubiere de graduar jure la opinión pía de nuestra Señora, estando jurada por la Universidad

El mismo allí, Constitución 8, titulo II. Don Felipe IV, la R.G. y don Carlos Segundo en esta Recopilación. 
Mandamos, que en la Universidad, que así lo hubiere votado, ninguno pueda recibir grado mayor de Licenciado, Maestro, ni Doctor en facultad alguna, ni aún el de Bachiller en Teología, si no hiciere primero juramento en un Libro Misal delante del que le ha de dar el grado, y los demás, que asistieren, de que siempre tendrá, creerá y enseñará de palabra y por escrito haber sido la siempre Virgen María Madre de Dios y Señora nuestra concebida sin pecado original en el primer instante de su ser natural, el cual juramento se pondrá, como lo hizo en el título, que del grado se despachare; y si sucediere haber alguno, lo cual Dios nuestro Señor no permita, que rehusare hacer el juramento, le será por el mismo caso denegado el grado, y el que se atreviese a dársele, incurra por el mismo caso en pena de cien ducados de Castilla para la Caja de la Universidad: y en privación de oficio el Secretario de la Universidad, que no lo denunciare ante el Rector. Y fiamos tanto de la devoción de todos para con la Madre de Dios, que nunca sucederá el caso de obligar a la ejecución de estas penas.

Ley Xiiii.

Q ue los que recibieren grados mayores, hagan la profesión de la Fe

Don Felipe Cuarto en Madrid a 3 de septiembre de 1624.

Conforme a lo dispuesto por el Santo Concilio de Trento y Bula de la Santidad de Pío Cuarto de feliz recordación, los que en las Universidades de nuestras Indias recibieren grados de Licenciados, Doctores y Maestros en todas facultades, sean obligados a hacer la profesión de nuestra Santa Fe Católica, que predica y enseña la Santa Madre Iglesia de Roma: y asimismo nos han de jurar obediencia y lealtad, y a nuestros Virreyes y Audiencias Reales en nuestro nombre, y a los Rectores de la tal Universidad, conforme a los Estatutos de ella.
Ley xxxxiiii.

Q ue los Catedráticos enseñen el Misterio de la limpia Concepción de nuestra Señora

Don Felipe IV en la Constitución 7, título 6. La Reina G. y Don Carlos Segundo en esta Recopilación.

Encargamos y mandamos, que cuando los Catedráticos llegaren a tratar, o leer materias en que suele leerse la cuestión de la limpieza de la Serenísima Virgen María nuestra Señora en su Concepción, no la pasen en silencio, y expresamente lean y prueben como fue concebida sin pecado original en el primer instante de su ser natural, pena de perder la Cátedra, y los cursos, que tuvieren los Estudiantes, que no denunciaren ante el Rector, el cual, hecha información del caso, de cuenta al Claustro, y ponga edictos de oposición a la Cátedra, y el que la perdiere por esta causa no pueda ser admitido a la oposición. ...

Ley Liii.

Que los Religiosos de Santo Domingo en Filipinas puedan leer Gramática, Artes y Teología

Don Felipe Cuarto en Madrid, a 27 de noviembre de 1623.

Con licencia de el Ordinario y Gobernador de las Islas Filipinas, y acuerdo de nuestra Real Audiencia de ellas, los Religiosos de la Orden de Santo Domingo en la Ciudad de Manila fundaron un Colegio, donde se lea Gramática, Artes y Teología, en que pusieron dos religiosos de cada facultad, y veinte colegiales seglares, de que ha resultado y resulta grande provecho a la juventud, predicación del Santo Evangelio, y enseñanza de los hijos de vecinos. Mandamos que por ahora, y entre tanto que no ordenaremos otra cosa, usen los dichos Religiosos de la licencia que el Gobernador les dio para fundar el Colegio, y leer en él las dichas facultades, y que esto sea y se entienda sin derogar, ni perjudicar a lo que está ordenado acerca de semejantes fundaciones, para que no se hagan, ni comiencen, sin expresa licencia nuestra, lo 
cual se ha de guardar en todas nuestras Indias sin excepción alguna". ${ }^{11}$

Todo lo anterior representaba un obstáculo y una limitante para emprender el camino hacia la búsqueda de la verdad mediante el método del conocimiento razonado de las cosas.

Al mismo tiempo que en España, a fines del siglo XIX, comienza a presentarse en la sociedad filipina un fuerte descontento social. Gran parte de la clase social protagonista reclamaba la derogación del sistema de coloniaje, el estatuto de provincia española de pleno derecho y la consiguiente representación filipina en cortes.

En 1880 surgió en Madrid el "Movimiento Propaganda", por el que los jóvenes malayos se deciden a utilizar plenamente las libertades de expresión que los frailes de Filipinas tenían prohibido en el ámbito colonial.

Sin embargo, fue hasta 1882 cuando la ideología de este grupo se logró consolidar, año en que José Rizal llegó a Madrid. José Protasio Rizal Mercado y Alonso Realonda recibió la educación humanista de los jesuitas de Manila. Rizal se constituyó en el líder natural del grupo a partir de un discurso que improvisa en un brindis con motivo de un homenaje que se rendía a dos pintores filipinos galardonados por la dirección de Bellas Artes. En el discurso, Rizal profesaba patriótica fe en una identidad propiamente filipina, a la vez que pedía, para la alejada colonia, los urgentes beneficios de la modernidad y, por supuesto, el fin de la hegemonía frailuna. También se proclamaba con especial convicción en la necesidad de intensificar la educación en las islas, a fin de rescatar al pueblo de tres siglos sin verdaderas luces. ${ }^{12}$

El pensamiento de Rizal se corresponde en el contexto de una época de ideas no sólo en la península, sino en lo que restaba de "las españas". La emancipación de las últimas colonias (Cuba, Puerto Rico y Filipinas) no se explica sin ese fermento de masonería, utopías románticas, krausistas, nihilismos y protosocialismos. $^{13}$

Ciertamente, existen muchos más elementos que nos permiten entender el escaso reconocimiento y la tradición del quehacer científico, como podría ser el peso de la explotación económica a que fue sometida la colonia. Sin embargo, la variable cultural de la religión católica en el desarrollo de la misma es un aspecto importante. En México, por ejemplo, en un discurso pronunciado por Justo Sierra (quien fue ministro de Instrucción Pública y Bellas Artes de 1905-1911), en apoyo del proyecto de ley que creó la Universidad Nacional, se destacan las ideas centrales de los positivistas que la habían promovido:

\begin{abstract}
"crear ciencia [...] La ciencia es laica [...] y no tiene más fin que estudiar fenómenos y llegar [...] a leyes superiores [...] Todo lo que de esta ruta se separe puede ser muy santo, muy bueno, muy deseable pero no es ciencia; por consiguiente, si la ciencia es laica, si las universidades se van a consagrar a la adquisición de verdades científicas, deberían ser [...] instituciones laicas". ${ }^{14}$

Actualmente, la influencia de la religión católica en Filipinas es quizá más poderosa que en cualquier otro país de América Latina, debido a que es una institución que tiene un fuerte peso en la vida política social y cultural del país. ${ }^{15}$ Aproximadamente 83 por ciento de los filipinos pertenecen a la religión católica, 5 por ciento son musulmanes, 3 por ciento pertenecen a la iglesia filipina independiente, 8 por ciento son protestantes y 3 por ciento son animistas y budistas.
\end{abstract}


Es paradójico que en Filipinas no se hable español, a pesar de que tiene 500 años de historia escrita, de los cuales 400 años han sido escritos en español. Sin duda para los filipinos esto representa una dificultad para comprender su pasado histórico cultural. Sin embargo, la nación filipina manifiesta gran parte de la cultura española al igual que otros países como México, Perú o Chile, y esto es más importante que el hecho de que en Filipinas no se hable el español.

Otro aspecto importante que limita el escaso quehacer científico en Filipinas, y que es de mucha actualidad, tiene que ver con el gasto que se destina a la formación de los recursos humanos y la distribución de éste en los distintos campos del conocimiento científico. Según datos del Banco Mundial, en términos per cápita, Estados Unidos destinó a la educación en 1995, 180 dólares por habitante, Singapur 80 dólares, Corea 37, Malasia 24, México 14 y Filipinas 1.8 dólares. Esto representa un monto total de 47257 millones de dólares en los Estados Unidos, 241 millones de dólares en Singapur, 1674 millones de dólares en Corea, 498 millones de dólares en Malasia, 1282 millones de dólares en México y 129 millones de dólares en Filipinas.

Finalmente, de acuerdo con el reporte del Banco Mundial de 1978-1998/99 donde se dan a conocer cifras que sirven como indicador del nivel científico y tecnológico alcanzado en cada país, es interesante observar que en los casos de México el número de ingenieros y científicos en los años 1981-1995 fue de 95 por cada millón de personas y en Filipinas de 90; sin embargo, en los Estados Unidos era de 3 732, en Corea del Sur 2636 y en Singapur 2 512. Esto nos indica en cierta manera, el grado de desarrollo y la importancia que para estos países representa el quehacer científico, sobretodo en áreas donde el conocimiento tiene un valor gregado mayor.

\section{Notas}

1. Caso, Alfonso. “Cultura y aculturación” en la comunidad indígena. Sep-Setentas-Diana. México, 1980. p. 67.

2. Foster, M. George, Ortiz, Fernando Spicer. H. Edward. et al. Aculturación. El Cayuco-Universidad Veracruzana. Xalapa, 1988. p. 1.

3. Rama, Angel. "Transculturación y género narrativo", en. Transculturación narrativa en América Latina. Siglo XXI, México, 1982, pp. 32 y 33.

4. Fortes, Jacqueline. Lomnitz, Larissa. La formación del científico en México. Siglo XXI. 1991 p. 16.

5. Habermas, Jürgen. Teoría de la acción comunicativa, I Racionalidad de la acción y racionalización social. Taurus, 1989. p. 289.

6. Op. cit. Fortes, Jaqueline. p. 16.

7. Abbagnano, Incola. Diccionario de filosofía. Fondo de Cultura Económica. 1995. p. 427.

8. Op. Cit. Fortones, Jaqueline. p. 17.

9. http://usuarios.tripod.es/Trivium/literatura/ Modernismo.htm, p. 1.

10. Fuentes, Carlos. El espejo enterrado. Fondo de Cultura Económica. Colección tierra firme. Primera reimpresión, marzo de 1993, p. 361.

11. http://www.filosofía.org/mfa/fae681a.htm

12.http://www.ensayo.rom.uga.edu/filósofos/filipinas/rizal/ introd.htm, p. 2.

13. http://www.ensayo.rom.uga.edu/filósofos/filipinas/rizal/ introd.htm, p 6.

14. Op. cit. Fortones, Jaqueline, p. 29.

15. Ramírez Bonilla, Juan José y Zapata Álvarez, Rodrigo. Filipinas. Asia Pacífico 1998. Centro de Estudios de Asia y África. El Colegio de México, mayo de 1999, p. 143 y Benítez L., Asunción. Filipinas. Asia Pacífico 1993. Centro de Estudios de Asia y África. El Colegio de México, 1993, pp. 106 y 108.

\section{Fuentes}

Carlos Fuentes. El espejo enterrado. Fondo de Cultura Económica. Colección Tierra Firme. Primera reimpresión. Marzo de 1993, p. 361; http://www.filosofía.org/mfa/ fae681a.htm

filipinas/rizal/introd.htm"; http://www.ensayo.rom.uga.edu /filósofos/filipinas/rizal/introd.htm, p. 2filipinas/rizal/ introd.htm"; http://www.ensayo.rom.uga.edu/filósofos/ filipinas/rizal/introd.htm, p 6; op. cit. Fortones, Jaqueline. p. 29; Ramírez Bonilla,Juan José y Zapata Álvarez, Rodrigo. Filipinas.Asia Pacífico 1998. Centro de Estuddios de Asia y África. El Colegio de México, mayo de 1999. p. 143 y Benítez L., Asunción. Filipinas. Asia Pacífico 1993. Centro de Estudios de Asia y África. El Colegio de México, 1993, pp. 106 y 108. 